\title{
Wide-Area Coordinated Control for Voltage Stability of Power System
}

\author{
Songkai Liu \\ School of Electrical Engineering \\ Wuhan University \\ Wuhan, China \\ Cheng Tian \\ School of Electrical Engineering \\ Wuhan University \\ Wuhan, China \\ e-mail:397000712@qq.com \\ Huimin Qiu \\ Beijing Electric Power Corporation \\ Beijing, China
}

\author{
Lin Chen \\ School of Electrical Engineering \\ Wuhan University \\ Wuhan, China \\ Liyi Kang \\ School of Electrical Engineering \\ Wuhan University \\ Wuhan, China \\ Tong Wang \\ School of Electrical Engineering \\ Wuhan University \\ Wuhan, China
}

\begin{abstract}
This paper presents a wide-area coordinated control strategy for voltage stability, which is based on multi-agent systems and wide area measurement system. The strategy combines the effectiveness of the Multi-layer secondary voltage control and the real time of wide area measurement system. It improves the voltage stability of power system by quickly and effectively controlling the voltage of the pilot bus. The proposed strategy has been verified in the IEEE 39 buses system.
\end{abstract}

Keywords- Multi-agent systems; wide area measurement system; voltage stability control

\section{INTRODUCTION}

Voltage stability has been an important security index of power system because of the formation of interconnection of major reg ional power grids, the west to east power transmission pattern and the practice of electricity market. Voltage stability control can prevent voltage collapse accident and improve the voltage stability of power system. All of existing control strategies for regulating control of reactive power generators are decentralized local control in the view of control level, there is no coordination between each decentralized control, so the voltage stability of system cannot be guaranteed, other security and economic are not enough [1-3].

Multi-Agent System (MAS) technology has matured in recent years. It is suitable for dynamic, distributed and open environment, and can effectively solve the complex control problems of geographical distribution and decentralization of control function [4-6]. At the same time, as the popularity of PMU (Phasor Measurement Unit) and the development of wide-area monitoring theory, formulating online PMU-based voltage stability analysis and control measures has been an effective way to achieve security and stability of power system [7-10]. Therefore, the combination of MAS and WAMS (Wide Area Measurement System) has a very important practical significance to voltage stability control.

\section{MAS NETWORK MODEL OF POWER SYSTEM AND WIDE AREA MEASUREMENT SYSTEM}

Power grid voltage stability control usually adopts the hierarchical distributed structure. The system is divided into layers of organization, coordination and execution to complete the corresponding task. Considering that the common goal of voltage stability control equipment in the same area is to maintain the voltage stability of regional power grid, so agents in the same area are formed a coordination layer. Intra-area information is managed by regional coordination agent. Communication and interaction between agents in different areas can be accomplished through coordination layers in each area. Based on this idea, a hierarchical distributed coordinated multi-agent network model for the grid voltage stability control is formed, as shown in Fig. 1.

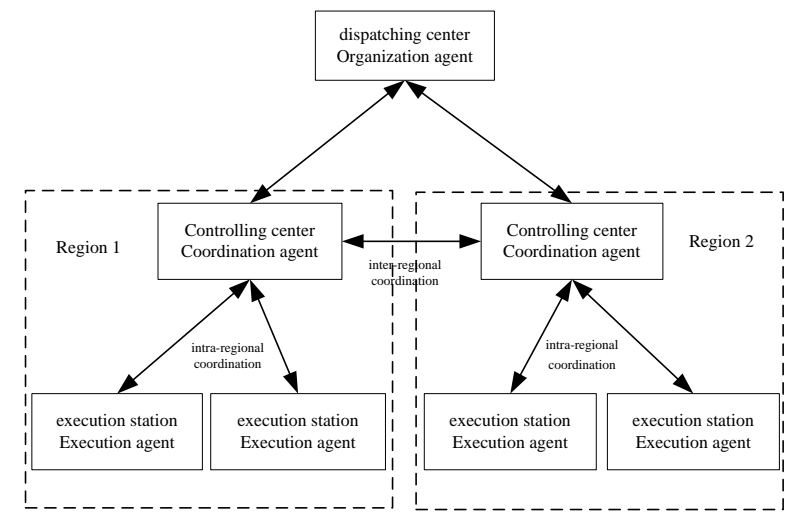

Figure 1. MAS network model of power system 
Wide Area Measurement System adopts the synchronous phas or measurement technology. Through the step-by-step layout of PMU in the key points of grid, the real-time high-speed acquisition of synchronous phasor and key data on the whole grid can be achieved. Collected data is transmitted to WAMS in real time through the power dispatching data network. Accordingly real-time monitoring, analysis and calculation for the grid in the case of normal operation and accident dis turbance are processed and the dynamic process of the power grid operation can be obtained and mastered timely. Based on the synchronization state information provided by the WAMS, the predicted security instability objective function of the key buses is created; the edge of the system voltage stability is calculated by equivalent impedance and voltage of the system. As voltage stability control system gains the stability indexes of buses from WAMS, comparing these indexes globally. If some indexes are outside the boundary of the voltage stability, coordinate control measures are executed immediately. In the meantime, the effect of voltage stabilization control is fed back by the WAMS. Then the control system further adjust with the feedback effect, thereby a stable voltage closed-loop control system is formed.

\section{MULTI-LAYER VOLT AGE COORDINATED CONTROL STRATEGY BASED ON WAMS}

\section{A. Multi-layervoltage control strategy}

The whole system is divided into a number of the approximate decoupling areas with multi-layer voltage control [11-17]. Then select the key bus as the pilot bus in each region and choose effective control bus for the corresponding pilot bus. In the operational process of the system, the secondary voltage controller determines the reference value of primary voltage controller by monitoring and analyzing the voltage amplitude of the pilot bus, so the voltage amplitude of the pilot bus is maintained near the set value and the voltage stability of the whole system is maintained. The Multi-layer voltage control diagram as shown in Fig. 2 and Fig. 3:
Control unit is responsible for the formulation and distribution of the control strategy within the region. Regional reactive power control signal $Q_{g}^{i}$ is got from the voltage deviation of pilot bus and transmitted to each generator in the region. The pilot bus voltage is lower than the set value when $\Delta Q_{\text {ref }}>0$ and generator reactive power output should be increased. Conversely reduce generator output.

If reactive power of all generators is less than the upper limit, regional reactive signal allocates reactive power between each generator unit in accordance with the proportion of reactive power margin, generator participation factor is calculated by regional coordination agent and allocated to each generator. Generator participation factor is calculated as follows:

$$
\begin{gathered}
Q_{R i}^{+}=\frac{Q_{g \text { max }}^{i}-Q_{g}^{i}}{\sum_{j}\left(Q_{g \text { max }}^{j}-Q_{g}^{j}\right)}\left(\Delta Q_{r e f}>0\right) \\
Q_{R i}^{-}=\frac{Q_{g}^{i}-Q_{g \text { min }}^{i}}{\sum_{j}\left(Q_{g}^{j}-Q_{g \text { min }}^{j}\right)}\left(\Delta Q_{r e f}<0\right)
\end{gathered}
$$

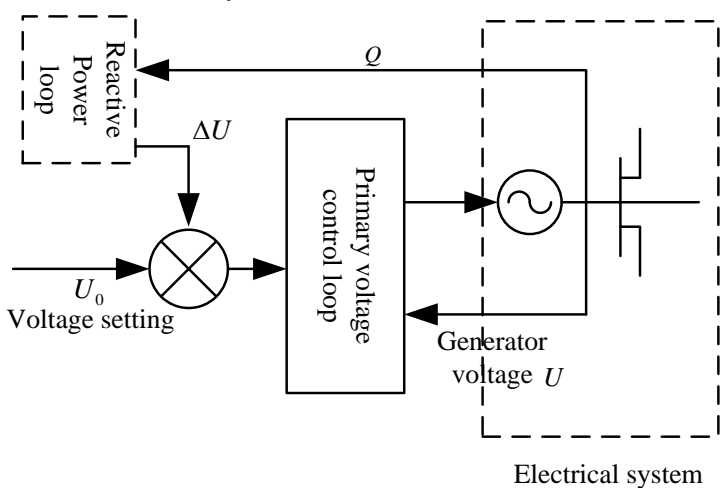

Figure 2. The primary voltage control diagram

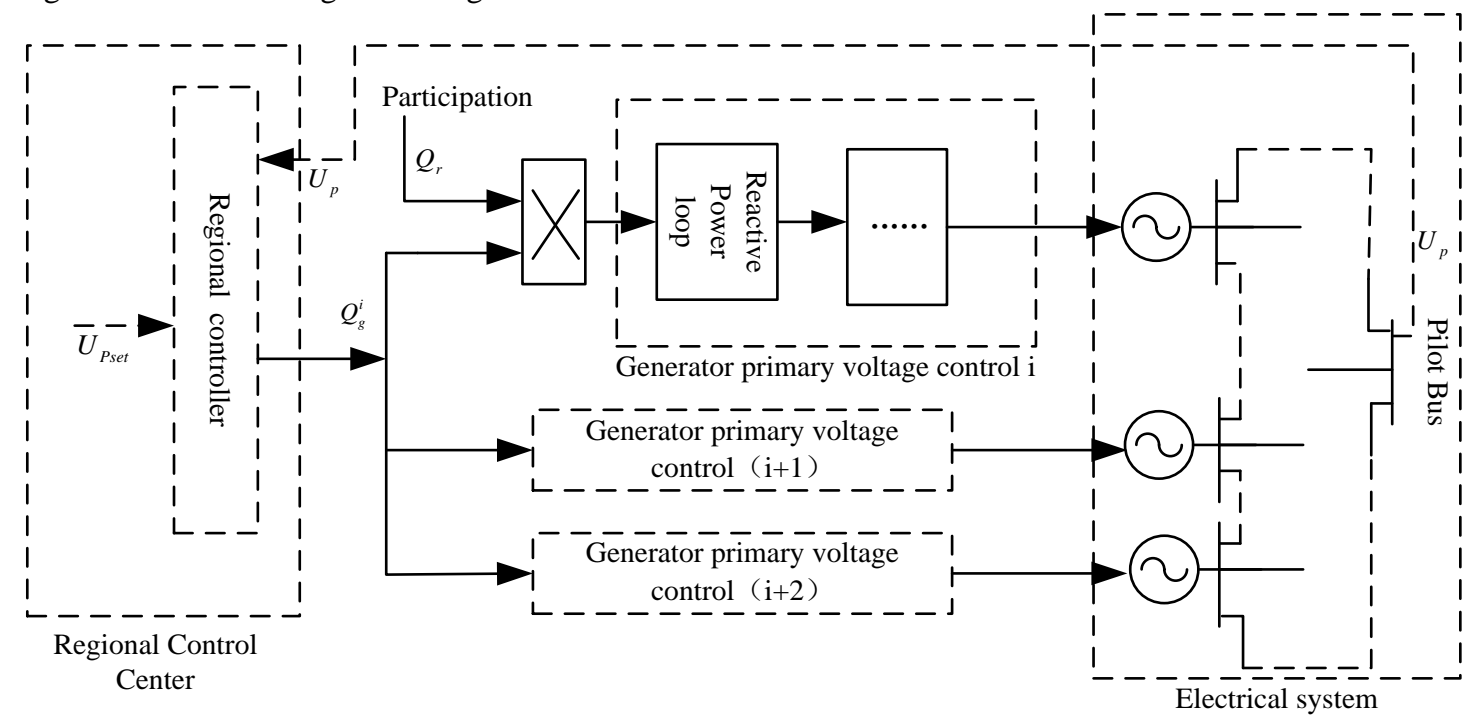

Figure 3. The secondary voltage control diagram 
where $Q_{g \text { max }}^{i}$ is the reactive power upper limit of generator unit, $Q_{g \text { min }}^{j}$ is the reactive power lower limit of generator unit, and $Q_{g}^{j}$ is the actual reactive power of generator unit.

The above formula is applied to the generators whose reactive power doesn't exceed the limit. The generator participation factor for generators whose reactive power beyond the upper and lower can be calculated as follows:

$$
\begin{aligned}
& Q_{R k}^{+}=Q_{g \text { max }}^{k}-Q_{g}^{k}\left(\Delta Q_{\text {ref }}>0\right) \\
& Q_{R k}^{-}=Q_{g}^{k}-Q_{g \text { min }}^{k}\left(\Delta Q_{r e f}<0\right)
\end{aligned}
$$

Through these formulas all participation factors of generators are gained and transmitted to the executive agents in primary voltage control by coordinative agents. Executive agents adjust their reactive power outputs according to the control parameters so as to maintain the systemvoltage level.

\section{B. Coordinated control strategy implementation}

Through the continuation power flow method [18-23] which is a basic method to solve the equilibrium point solution trajectory of the nonlinear flow equations the complete PV Curves can be sketched and the bifurcation point of continuous trend is obtained. Taking advantage of the bifurcation point information useable in the voltage stability analysis and control, the voltage stability control is sues can be effectively solved.

The linear form of the power flow equations is

$$
\left[\begin{array}{c}
\Delta P \\
\Delta Q
\end{array}\right]=\left[\begin{array}{ll}
J_{P \theta} & J_{P U} \\
J_{Q \theta} & J_{Q U}
\end{array}\right]\left[\begin{array}{c}
\Delta \theta \\
\Delta U
\end{array}\right]
$$

where $\Delta P$ is the active micro-increment change of the bus, $\Delta Q$ is the reactive micro-increment change of the bus, $\Delta \theta$ is the voltage angle micro-increment change of the bus and $\Delta U$ is the voltage micro-increment change of the bus.

Take singular value analysis to $J$, $J=V \sum U^{T}=\sum_{i=1}^{2 n-m} V_{i} \delta_{i} U_{i} \quad$ where singular value vector $V_{i}$ and $U_{i}$ are $i$ column of normalized matrices $V$ and $U$.

When the minimum singular value of the system is close to 0 , the system is close to the voltage collapse point, The state of the system is completely determined by the minimum singular value $\delta_{2 n-m}$ and its corresponding singular vectors $V_{2 n-m}$ and $U_{2 n-m}$. Therefore $\left[\begin{array}{c}\Delta \theta \\ \Delta U\end{array}\right]=\delta_{2 n-m}^{-1} U_{2 n-m} V_{2 n-m}^{T}\left[\begin{array}{c}\Delta P \\ \Delta Q\end{array}\right]$ and the maximal tabulated value of matrix $V_{2 n-m}$ means the most sensitive direction of the change of active and reactive power injection, from which the most dangerous change model of load and generated energy. The maximal tabulated value of matrix $U_{2 n-m}$ means the most sensitive electricity voltage, from which vulnerable buses are identified. The voltage stability marg in can be expressed by the minimum singular value of Jacobian matrix $\delta_{\min }$. The system is close to the limit of voltage stability while $\delta_{\min }$ is close to 0 , conversely the systemis safe enough.

The singular value decomposition method can be used to calculate the sensitivity of the system voltage stability margin of the state and control variables. From the basic definition of singular value analysis, it can be got $J^{T} J U=\delta_{\min }^{2} U ; J J^{T} V=\delta_{\min }^{2} V$.

Where $U=u_{\text {min }}, V=v_{\text {min }}$.

According to the sensitivity of the minimum singular value to the state variables the vulnerable areas of the system can be determined and the reactive power allocation can be programmed reasonably. The function of each adjustment of the control parameters to the system voltage stability can be reflected by the sensitivity. Accordingly suitable generators can be chosen to control the system.

The sensitivity of the minimum singular value to the control variables are $\left[\frac{\partial \delta_{\min }}{\partial X}\right]=\left[\frac{\partial \delta_{\min }}{\partial x_{1}}, \cdots, \frac{\partial \delta_{\min }}{\partial x_{m}}\right]^{T} \in R^{m}$ $\left[\frac{\partial \delta_{\min }}{\partial Y_{s}}\right]=\left[\frac{\partial \delta_{\min }}{\partial y_{1}}, \cdots, \frac{\partial \delta_{\min }}{\partial y_{m}}\right]^{T} \in R^{m}$

and

The steps of multi-layer voltage controlstrategy

In this paper, through the introduction of PMU technology multi-layer voltage stability control has been improved. The basic idea is real-time measurement of buses information by PMU installed in pilot buses without repeated flow calculation, and then send the information to the coordination agents of MAS. Coordination agent will calculate the flow of each reactive power generator with choosing appropriate control strategy and transmit control signal to executive agents. Executive agents will control the reactive power generators so as to achieve the purpose of voltage stability.

The steps of multi-layer wide-area coordinative control strategy of voltage stability:

Measuring the phasor information of pilot buses before and after disturbance with PMU.

Calculating voltage stability margin of each bus according to the difference between the two samples. Then determine to take local control strategy or regional coordination controlstrategy.

Calculating the corresponding control law with voltage deviation, selecting reactive power generators which should participate in the control and re-setting parameters of them.

Re-sampling phase value of the system and calculating voltage stability margin again to determine the effectiveness of control measures. Take e mergency control to reactive power generator if the control law is effective. Conversely turn to Step 2.

\section{SIMULATION RESULTS}

In this paper, the test is performed on the IEEE 39 buses system with the proposed method. The interference of load sudden increase at load bus is considered. Assuming that the load in bus 15 and 16 jump $70 \%$. Taking three kinds of voltage stability control measures, no control, intra-regional control and inter-regional 
coordination control, to the general bus 16 and pilot bus 23 and analyzing their effects.

Firstly, find the Jacobian matrix of the system near the voltage collapse point. Then take minimum singular value analys is to it and determine the control sensitivities of all generators. The control sensitivity of different generator is shown in TABLE I.

TABLE I. THE CONTROL SENSITIVITY OF DIFFERENT GENERATOR

\begin{tabular}{c|c||c|c}
\hline \hline generator & sensitivity & generator & sensitivity \\
\hline 30 & 0.07 & 35 & 0.68 \\
\hline 31 & 0.03 & 36 & 0.79 \\
\hline 32 & 0.09 & 37 & 0.12 \\
\hline 33 & 0.26 & 38 & 0.04 \\
\hline 34 & 0.29 & 39 & 0.01 \\
\hline \hline
\end{tabular}

The results, as shown in Table 1, shows that for bus 15 and 16 in this operating condition, the intra-regional control buses is bus 35 and 36, while inter-regional coordinated controlbuses is 33 and 34 .

For the general bus 16, the effect contrast of different control strategies is shown in TABLE II:

TABLE II. EFFECT CONTRAST OF DIFFERENT CONTROL STRATEGIES FOR BUS 16

\begin{tabular}{c|c|c|c}
\hline \hline Control strategy & $\begin{array}{c}\text { no } \\
\text { control }\end{array}$ & $\begin{array}{c}\text { intra- } \\
\text { regional } \\
\text { control }\end{array}$ & $\begin{array}{c}\text { inter- } \\
\text { regional } \\
\text { control }\end{array}$ \\
\hline Initial voltage value & 1.0344 & 1.0344 & 1.0344 \\
\hline $\begin{array}{c}\text { Recovery voltage } \\
\text { value }\end{array}$ & 0.98037 & 1.02138 & 1.0314 \\
\hline $\begin{array}{c}\text { Voltage deviation } \\
\text { The percentage of } \\
\text { voltage deviation }\end{array}$ & 0.0540 & 0.0130 & 0.0030 \\
\hline \hline
\end{tabular}

It can be seen from Table 2, inter-regional coordination control of the generator can effectively improve the voltage level of the power system.

Multi-layer voltage control can effectively maintain the voltage level of the pilot bus, the control effect for the pilot bus 23 can better reflect the voltage control level of the whole system, the control effects contrast of different control strategies for bus 23 is shown in TABLE III:

TABLE III. T ABLE III. EFFECT CONTRAST OF DIFFERENT CONTROL STRATEGIES FOR BUS 23

\begin{tabular}{c|c|c|c}
\hline \hline Control strategy & $\begin{array}{c}\text { no } \\
\text { control }\end{array}$ & $\begin{array}{l}\text { intra- } \\
\text { regional } \\
\text { control }\end{array}$ & $\begin{array}{c}\text { inter- } \\
\text { regional } \\
\text { control }\end{array}$ \\
\hline $\begin{array}{c}\text { The initial voltage } \\
\text { amplitude }\end{array}$ & 1.046 & 1.046 & 1.046 \\
\hline $\begin{array}{c}\text { Recovery voltage } \\
\text { amplitude }\end{array}$ & 1.0117 & 1.0336 & 1.0457 \\
\hline Voltage deviation & 0.0343 & 0.0124 & 0.0003 \\
\hline $\begin{array}{c}\text { The percentage of } \\
\text { voltage deviation }\end{array}$ & $3.28 \%$ & $1.19 \%$ & $0.03 \%$ \\
\hline \hline
\end{tabular}

This shows that the intra-regional coordinated control can significantly increase the voltage level of the system, and the control effect of inter-regional coordinated control is better than the intra-regional control.

\section{CONCLUSIONS}

In this paper, the coordinated control strategy based on MAS and WAMS has both the effectiveness of Multiagent secondary voltage stability control and the advantage of the real-time wide-area measurement system. Firstly, the proposed strategy can improve voltage stability margin of the system and provide a good reference for operator to effectively control. Secondly, all reactive power generators of the system can be fully utilized to improve the voltage control effect. At last, the phas or information of WAMS is fully utilized. It cannot only improve the speed of voltage stability analysis and control, but also can better reflect the dynamic nature of the control process.

In short, the coordinated control strategy presented in this paper can improve the voltage stability of power systemtimely and effectively.

\section{REFERENCES}

[1] X. Y. Zhou, "Research on Power System Voltage Stability and Control," Hangzhou: Zhejiang University, 2006.

[2] H. Q. Li, Y. M. Liu, N. Yorino, "VOLTAGE ST ABILITY ASSESSMENT FOR SADDLE BUS BIFURCATION AND LIMIT INDUCED BIFURCATION," Proceedings of the CSEE, vol. 25, no. 24,pp. 56-60, 2005.

[3] Y. X. Yu, "REVIEW ON VOLTAGEST ABILITY STUDIES," Automation of Electric Power Systems, vol. 23, no. 21, pp. 1-8, 1999.

[4] M. J. Zhang, L. X. Cao, J. W. Li et al., "MULTI-AGENT SYSTEM FOR VOLTAGE/VAR "OPTIMIZATION CONSIDERING MULTI-REGIONAL POWER SYSTEMS," Automation of Electric Power Systems, vol. 28, no. 17, pp. 70-74, 2004.

[5] Reynaldo, Francisco, Nuqui, "State Estimation and Voltage Security Monitoring Using Synchronized Phasor Measurements," Dissertation Submitted to the Faculty of the Polytechnic Institute and State University in Partial Fulfillment of the Requirements for the Degree of Doct or of Philosophy in Electrical Engineering, pp. 32-47, 2001.

[6] Borka Milošević, "On Voltage Stability Monitoring and Control Using Multi-agent System," School of Electrical and Computer Engineering, Georgia Institute of Technology, pp.9-17, 2002.

[7] W. T. Zhang, Y. F. Qiu, X. J. Zheng, "GPS AND ITS APPLICATION IN POWER SYSTEM," Power System Technology, vol. 20, no. 5,pp. 38-45, 1996.

[8] Q. Guo, X. P. Liu, S. R. Lv et al., "GPS synchronized clock for power system transient stability prediction and control," Automation of Electric Power Systems, vol. 22, no. 6, pp. 11-13, 1998.

[9] X. H. Qin, "Study on WAMS Based Power Systems State Estimation and Stability Assessment," Beijing: North China Electric Power University, 2008.

[10] C. Y. Yan, "Related Technologies of WAMS and Study on Application of Voltage Stability," Beijing: North China Electric Power University, 2005.

[11] L. Fan, and H. Chen, "STUDY OF SECONDARY VOLTAGE CONT ROL," Automation of Electric Power Systems, vol. 24, no. 11, pp. 18-21, 2000.

[12] Y. Zhao, "The Research of Hierarchical Voltage Control System," Beijing: North China Electric Power University, 2004.

[13] Y. Z. Sun, X. Y. Yao, F. Liu, "THE IMPACT OF SECONDARY VOLTAGE CONTROL ON POWER SYSTEM STABILITY," Proceedings of the CSEE, vol. 20, no. 2, pp. 28-32, 2000. 
[14] J. P. Paul, J. Y. Leost, J. M. Tesseron, "Survey of Secondary Voltage Control in France: Present Realization and Investigations," IEEE Trans on Power Systems, vol. 2, no. 2, pp. 505-51 1, 1987.

[15] X. Q. Ding, W. Huang, W. J. Zhang et al., "A PILOT BUS VOLT AGE CORRECTION METHOD BASED ON VOLTAGE CONT ROL AREA," Power System Technology, vol. 28, no. 14, pp. 44-48, 2004.

[16] K. P. Wang, "The Study of Secondary Voltage Control in Power System," Beijing: North China Electric Power University, 2003.

[17] J. Y. Wen, Q. H. Wu, D. R. Turner, "Optimal Coordinated Voltage Control for Power System Voltage Stability," IEEE Trans on Power Systems, vol. 19, no. 2, pp. 1115-1 122, 2004.

[18] L. Li, "The Study of Power System Voltage Stability Based on Continuation Power Flow," Chengdu: Southwest Jiaotong University, 2011.
[19] H. Y. Wang, L. Cai, Z. J. Qi, "Improved Cont inuation Power Flow in Tracing PV Curves of Power Systems," Electrical Engineering, no. 7, pp. 28-31,2011.

[20] L. Wu, T. T. Gu, L. X. Yao, "Static Voltage Stability Analysis Based on Improved Continuation Power Flow," Power System Technology, vol. 35, no. 10, pp. 99-103, 2011.

[21] J. Li, J. J. Chen, S. Si, "Calculation of static voltage stability margin based on continuation power flow and immune genetic algorithm," Power System Protection and Control, vol. 38, no. 18, pp. 24-27, 2010.

[22] H. B. Sun, X. Li, M. H. Zhang et al., "Continuation Power Flow Method Based on Dynamic Power Flow Equation," Proceedings of the CSEE, vol. 31, no. 7, pp. 77-82, Mar. 2011.

[23] H. Wu, Z. N. Wei, C. L. Wang et al., "Voltage stability study based on synthesis method of continuous power flow," Power System Protection and Control, vol. 39, no. 6, pp. 99-104, Mar. 2011. 